\title{
La interferencia de la Iglesia Católica en la ampliación de los derechos sexuales y reproductivos en Chile. El caso de la despenalización parcial del aborto en 2017
}

\author{
The interference of the Catholic Church in the extension of sexual and \\ reproductive rights in Chile. The case of the partial decriminalisation of abortion \\ in 2017
}

\author{
Alix Puraye \\ puraye.alix@gmail.com \\ Universidad de Rouen, Francia
}

Recepción: 01 Marzo 2021

Aprobación: 24 Junio 2021

Publicación: 01 Septiembre 2021

Cita sugerida: Puraye, A. (2021). La interferencia de la Iglesia Católica en la ampliación de los derechos sexuales y reproductivos en Chile. El caso de la despenalización parcial del aborto en 2017. Descentrada, 5(2), e147. https://doi.org/10.24215/25457284e147
Resumen: En Chile, la cuestión de los derechos sexuales y reproductivos -impensable durante mucho tiempo en una dictadura caracterizada por un machismo estructural- empieza a plantearse en los años 90, en una democracia todavía marcada por los enclaves del antiguo régimen autoritario. Su ampliación se ve aún hoy fuertemente obstaculizada por un actor históricamente decisivo en la vida política del país: la Iglesia Católica. Apoyándose en un conjunto heterogéneo de actores, esta ha puesto en marcha una estrategia retórica y activista muy eficaz para retrasar la agenda feminista, restringiendo al máximo la promulgación de leyes reñidas con su concepción esencialista de la mujer y de la familia. A través de un recorrido histórico de la relación entre Iglesia Católica y luchas feministas, y del análisis del caso de la despenalización parcial del aborto en 2017, este estado del arte nos permitirá entender a la vez cuándo y cómo se produce la escisión político-ideológica entre estos dos actores o, más bien, cuándo dejan de ser aliados. Asimismo, a través del ejemplo del aborto, se verá cuáles son las estrategias diseñadas por la jerarquía para luchar contra la amenaza que representa la ampliación de los derechos sexuales y reproductivos, esta es, la encarnación de la "ideología de género" y la "cultura de la muerte".

Palabras clave: Iglesia Católica, Derechos sexuales y reproductivos, Feminismo, Aborto, Cultura de la muerte.

Abstract: In Chile, the issue of sexual and reproductive
rights - unthinkable for a long time under a dictatorship
characterised by structural machismo- began to arise in the
1990 s, in a democracy still marked by the remnants of the
former authoritarian regime. The expansion of these rights is
still strongly hampered today by a historically decisive actor in
the country's political life: the Catholic Church. Relying on a
heterogeneous set of actors, it has carried out a very effective
rhetorical and militant strategy to delay the feminist agenda
by restricting as much as possible the enactment of laws that
interfere with its essentialist conception of women and the
family. The case of the partial decriminalisation of abortion in
2017 is archetypal to the extent that the political character of
feminist arguments in favour of women's autonomy - and of 
their bodies - clashes with the moral doctrine of the Church, which sees abortion as the embodiment of the "gender ideology" and the "culture of death".

Keywords: Catholic Church, Sexual and reproductive rights, Feminism, Abortion, Death culture.

\section{INTRODUCCIÓN}

La Iglesia Católica se ha presentado desde la independencia de Chile como la institución unificadora y conciliadora del país, en torno a la cual se estructuró la "identidad nacional" (Sánchez Gaete, 2009, p. 22). Bajo esta premisa, la Iglesia Católica adquirió una legitimidad moral en Chile que le permitió consolidar un espacio político y, así, incidir en la política estatal. Aunque la Constitución de 1925 oficializó la separación entre la Iglesia y el Estado (Sánchez Gaete, 2014), la autoridad eclesiástica siguió ejerciendo un papel fundamental en el Estado chileno, en asuntos como el desarrollo del sistema educativo o la defensa de los sectores más relegados de la sociedad. En los meses anteriores al golpe de Estado, el arzobispo de Santiago y presidente de la Conferencia Episcopal de Chile, Raúl Silva Henríquez, asumió, en vano, un papel de mediador entre el presidente Allende y los principales líderes de la Democracia Cristiana, Eduardo Frei Montalva y Patricio Aylwin, con el fin de evitar el quiebre de la democracia (Pacheco Gómez, 2012). Ya en dictadura, la Iglesia jugó un papel destacable ayudando a las víctimas de la represión mediante organizaciones como el Comité de Cooperación para la paz en Chile (COPACHI) y la Vicaría de la Solidaridad. Con la vuelta de la democracia, la Iglesia volvió a consolidar su imagen de ente conciliador al participar activamente en la redacción de los informes Rettig y Valech sobre las violaciones a los derechos humanos ocurridos en el período 1973-1991.

Si bien el número de católicxs ha bajado desde hace algunos años, ${ }^{1}$ la Iglesia sigue aupada por esta imagen de mediadora, lo que le permite continuar ejerciendo una presión considerable sobre la agenda estatal, específicamente a la hora de abordar cuestiones que chocan con su sistema de valores, como cada vez que se pretende legislar sobre asuntos como los derechos reproductivos y sexuales, o de la autonomía de las mujeres en general. La cosmovisión católica choca con el activismo feminista que, justamente, pretende superar semejante marco teórico-normativo de opresión y exclusión basado en la idea de que el papel que debe desempeñar la mujer en la sociedad viene condicionado por sus funciones biológicas.

Hoy en día, la relación de la Iglesia Católica con los movimientos feministas es muy tensa. Para dicha institución, luchas tales como la ley del divorcio, la legalización del aborto, la educación sexual integral, entre otras, apelan directamente a un relativismo sexual que constituye una amenaza e, incluso, una negación de sus valores. Dentro del conjunto heterogéneo de actores que luchan contra estos cambios -sean grupos religiosos, ONGs u actores individuales que ejercen como juristas, abogados, médicos, bioeticistas o psicólogos-, la Iglesia Católica ocupa un lugar preponderante (Morán, 2018). Si bien estos actores pueden recibir apoyo de otras instituciones como las iglesias evangélicas que tienen un papel cada vez más pujante en la sociedad chilena, en este trabajo nos enfocaremos sólo en el papel de la Iglesia Católica puesto que la clase dirigente chilena, la que tiene más capacidad de influir en la aprobación de leyes, sigue todavía muy vinculada y apegada a los valores que promueve.

Su incidencia en la obturación de los derechos sexuales y reproductivos se dio a través de la implementación, a partir de los años 90, de un "secularismo estratégico". Bajo este concepto forjado por Juan Marco Vaggione (2017) se señala una serie de estrategias que pretenden contrarrestar la ampliación de este tipo de derechos mediante un desplazamiento discursivo y militante hacia lo secular, que puede ser explícito u oculto. Para desactivar la revolución inducida por la politización de lo sexual y de lo reproductivo que emana del feminismo occidental desde los años 70 y que socava su comprensión de la ley natural, la autoridad eclesiástica 
acuñó dos expresiones: la "cultura de la muerte" y la "ideología de género". La primera salió por primera vez en la encíclica Evangelium Vitae (Juan Pablo II, 1995) y sirve para denunciar los discursos, normas jurídicas, personas y organizaciones que, supuestamente, se mostrarían poco favorables a la vida al contemplar como tolerable la posibilidad de acabar con ella en ciertas circunstancias. El blanco de esta expresión son lxs defensorxs del derecho a una muerte digna (eutanasia, suicidio asistido) y del derecho a la interrupción del embarazo. El segundo concepto fue teorizado más recientemente por pensadores católicos estadounidenses cuyo uso se generalizó dentro del ámbito militante católico (Vaggione, 2017). El objetivo en este caso es anular la validez de los estudios de género (gender studies) que postulan que las diferencias entre hombres y mujeres son constructos sociales. A su juicio, al "negar" la dimensión y metodología científica de estos estudios, reducen el género a una mera creencia, una invención "sin fundamentos reales".

En lo que sigue, por medio de un análisis bibliográfico, se mostrará cómo la lucha por los derechos sexuales y reproductivos en Chile se ha visto obstaculizada por el dominio de la Iglesia Católica sobre el campo de lo sexual. En este sentido, nos preguntaremos por su rol en el desplazamiento o neutralización de la cuestión política de la que, precisamente, surgen los activismos feministas y LGBTIQ+. ¿Cuándo se produce y cuáles son los factores que desembocan en la ruptura entre luchas feministas e Iglesia Católica? ¿Cuáles son los repertorios políticos usados por la jerarquía para contrarrestar los derechos sexuales y reproductivos? ¿Cómo se despliega el secularismo estratégico en Chile? Finalmente, ¿cómo éste se concretiza en el proceso de despenalización parcial del aborto?

Para contestar estas preguntas, en primera instancia, veremos en qué medida el proyecto moral y cultural de la Iglesia Católica choca con el de los movimientos feministas, a través de una recopilación de antecedentes históricos, prestando particular atención al cambio de relación entre la Iglesia y las mujeres durante los años de la dictadura militar. Luego, analizaremos a través de qué instancias concretas y marcos teórico-conceptuales se da el secularismo estratégico. Dedicaremos la última parte a analizar cómo la Iglesia Católica logró interferir en el proceso de despenalización del aborto en 2017, por medio de su restricción jurídica y social. Este caso es paradigmático de la tenacidad de la Iglesia para perpetuar su ideal heteronormativo.

\section{La Iglesia Católica y los MOVimientos FEMinistas De los aÑos '30 Hasta HOY: DEL CONSENSO A LAS DISCREPANCIAS}

Históricamente, las mujeres chilenas han sido relegadas al campo de lo improductivo, ejerciendo labores como amas de casa, amansadoras, cosecheras, tejedoras, etc. (Zamorano, 2008). Eran un medio, una mano de obra invisible, calladas y sumisas, reducidas a su capacidad reproductiva y de crianza de los hijos, para asegurar el buen funcionamiento de la sociedad chilena. Así lo expresa Kirkwood: "[la mujer] carece de una identidad de ser que le sea propia. Es meramente un vínculo" (2010, p. 29). En este sentido, la autora expone que la sociedad ha despojado a las mujeres de su condición de sujetos a fin de reproducir un orden socio-normativo patriarcal, que tiene como núcleo la familia heterosexual en donde se condensa la funcionalidad que se espera de ellas.

Este "deber ser", que se ha ido cristalizando y erigiendo en normas por medio de instituciones como el Estado, la escuela o la Iglesia, cuaja en una lógica de control de los cuerpos de las mujeres que entrabará hasta los inicios del siglo XX su proceso de emancipación e individuación. En muchos casos, este disciplinamiento respondía a problemas políticos, por ejemplo, el control del linaje durante la época colonial: "Las mujeres son la puerta de entrada y salida de los órdenes que estructuran la sociedad colonial en tanto sociedad de castas" (Araya Espinoza, 2008, p. 33). Esta excesiva vigilancia hacia las mujeres estaba fuertemente impregnada por la retórica clerical que entendía a la mujer como sujeto subordinado reducido a sus capacidades reproductivas. En efecto, en aquel entonces, el vientre de la mujer podía ser sinónimo de corrupción del orden simbólico establecido si ella daba a luz a mestizos o "plebe”. Esta desviación de la norma 
estaba asociada a las ideas de mancha, putrefacción y pecado. Al revés, se honraba a las monjas que encarnaban el ideal de castidad y pureza (Araya Espinoza, 2008).

Ya a partir de mediados del siglo XVI, y cada vez más claramente con el tiempo, adquirió una legitimidad tal que el imaginario social y las relaciones intersubjetivas están todavía profundamente permeados por su cosmovisión. Asimismo, algunas profesiones históricamente desempeñadas en exclusiva por mujeres -aunque hoy su formación ya no se basa en criterios de género-, siguen estando marcadas por una presencia femenina muy fuerte. Según el Informe sobre Brechas de Personal de Salud por Servicio de Salud, en 2017, en el sector médico, el $90 \%$ de las matronas y el $88 \%$ de las enfermeras eran mujeres. ${ }^{2}$ Se trata de profesiones que, además de conjugarse muy raramente con el ámbito masculino, resaltan las supuestas cualidades de la esposa virtuosa retratadas en la Biblia. ${ }^{3}$ Este arraigo de la doctrina católica dentro del ámbito social y sexual permitió a la Iglesia tener una influencia notable en la vida política del país, así como en el delineamiento de sus fronteras legales y morales (Peñas Defago y Morán Faúndes, 2015).

La persistencia hasta en la actualidad de esta doctrina conservadora -que orienta a las mujeres hacia profesiones que corresponden a sus supuestas cualidades innatas-, no ha impedido que grupos de mujeres se organizaran para hacer valer sus derechos fundamentales y su legitimidad en la esfera pública desde mucho antes. Este protagonismo de las mujeres en la historia fue ampliamente ignorado en la historiografía hasta la segunda mitad del siglo XX. En Chile, la construcción de un nuevo conocimiento histórico y las nuevas perspectivas de lectura del pasado, que dieron lugar a investigaciones sobre temas inéditos, fueron de la mano con el paulatino reconocimiento de la academia hacia el trabajo de las historiadoras, especialmente a partir de los años de la transición democrática (Cabrera Gómez y Errázuriz Tagle, 2015). Si bien estas investigaciones estaban inicialmente teñidas de una cierta visión "miserabilista" de la mujer, que la cristalizaba como un sujeto de segunda categoría, después han surgido nuevas corrientes historiográficas como la Nueva Historia de la Mujer, cuyo enfoque se centraba en cambio en sus "disímiles manifestaciones de rebeldía y resistencia" (Gaviola, Largo y Palestro, 1994).

Gracias a estos estudios, vemos que, desde finales del siglo XIX, pero sobre todo a partir de los años 30, el fervor feminista chileno se empieza a fraguar: la creación del Movimiento pro emancipación de la Mujer (MEMCH) que abogaba por la integración política de la mujer y el nacimiento del Partido Femenino de Chile en 1946, que luchó por obtener el derecho al voto para las mujeres, son ejemplos claros del afán participativo de las mujeres. Si bien generaron mucha polémica, estas movilizaciones femeninas que se enfocaban en la consecución de derechos políticos no cuestionaban fundamentalmente las identidades de género, por lo que no amenazaban la Iglesia Católica. A modo de ejemplo, en el caso de la lucha por el derecho a voto, que apareció como tema en 1865, son los valores que la Iglesia Católica abarcaba los que impulsaron a las primeras mujeres a abogar por sus derechos. Se trataban sobre todo de mujeres de clase alta que se reunieron para defender los intereses y valores de la Iglesia, como la beneficencia y la caridad. Por su educación, tuvieron los recursos necesarios para entender que sólo a través de la visibilización política de la mujer se podían obtener derechos políticos -y no civiles, los que la mayoría consideraba más importantesque pudieran legitimar el ejercicio de su ciudadanía (Errázuriz Tagle, 2005). Esta lucha por el derecho al voto femenino ha sido incluso provechosa para la Iglesia, ya que no sólo el discurso de las mujeres legitimaba sus valores, reificaba la tríada mujer/esposa/madre, sino también porque ellas tendían a votar por partidos conservadores (en aquel entonces, el Partido Conservador). Por consiguiente, la jerarquía no veía con malos ojos la integración social de las mujeres en la esfera pública y los avances sociales que se estaban produciendo a su respecto. Esta relación perduró hasta la primera década de la dictadura militar, en la que tanto la jerarquía eclesiástica como las mujeres movilizadas estaban en primera línea de la resistencia, de la ayuda a los más desfavorecidos, en un contexto de aumento de la pobreza, severa crisis económica y violación flagrante de los derechos humanos (Gaviola, Largo y Palestro, 1994).

Primero, durante las décadas de los 60 y 70 surgió, en América Latina, la teología de la liberación, una corriente dentro de la Iglesia Católica acicateada por el Papa Juan XXIII, que se caracterizaba por una 
preocupación por la caridad hacia los sectores más desfavorecidos racial y económicamente, así como por una especial atención a los problemas socioeconómicos del país (Gutiérrez, 1972). Encontró un gran eco en América Latina, tanto en el sector protestante como en el católico, especialmente en Chile. En 1971, un año después de la llegada al poder de Salvador Allende con la Unidad Popular (UP), se creó el movimiento Cristianos por el Socialismo (CpS), el cual no estuvo exento de críticas dentro de la propia Iglesia Católica. Aunque sólo duró dos años, los ideales socialistas que difundía fueron el motor de la resistencia durante los años de dictadura, ya que la jerarquía eclesiástica fundó posteriormente varias organizaciones con el objetivo de ayudar a los perseguidos políticos, además de proporcionar ayuda a los opositores al régimen para exiliarse e informar a otros países de las tensiones del país (Cruz Contreras, 2015).

Este tipo de solidaridad también se dio en agrupamientos de mujeres opositoras a la dictadura. Se estima que, al inicio de la dictadura, el 70\% de las chilenas seguían circunscritas al trabajo doméstico no remunerado (Gaviola, Largo y Palestro, 1994). Algunas de ellas se reunían en los Centros de Madres o en las parroquias donde hablaban de su vida cotidiana; otras, en asociaciones como la Agrupación de Familiares de Detenidos Desaparecidos (AFDD); y otras ya habían incursionado en la arena pública. ${ }^{4}$ En este sentido, se trataba de organizaciones femeninas que no ponían en tela de juicio los roles tradicionalmente asignados a su género ni las relaciones de dominación entre mujeres y hombres, instalados dentro del Estado y promovidos por la Iglesia Católica. En efecto, "se trata de un período en que la 'integración social' de la mujer fue dejando implícita una aceptación de la desigualdad en tanto no cuestionaba los mecanismos profundos de su opresión y en cuanto se trataba del único sector organizado que no se planteaba desde su propia liberación" (Gaviola, Largo y Palestro, 1994, p.26). Muchas mujeres también acudían a organizaciones claves de la resistencia fundadas por la misma jerarquía, tales como la Cooperación para la paz en Chile (COPACHI), la Fundación de Ayuda de las Iglesias Cristianas (FASIC) o el Comité Pro Paz -disuelto por la Junta Militar y reemplazado después por la Vicaría de la Solidaridad-, todas impulsadas por el cardenal Raúl Silva Henríquez.

Esta relación de colaboración y apoyo cambió a partir de los años ' 80 . Durante este período, estos grupos -tanto las organizaciones de mujeres como la Iglesia Católica-, experimentaron un cambio de paradigma en su seno, que dio lugar a una exaltación de las tensiones entre ambos. Para las mujeres, la década de los ' 80 fue clave en el nacimiento o actualización de una verdadera conciencia feminista, de ahí el cambio semántico: muchas organizaciones femeninas se volvieron feministas. Esta reflexión se llevó a cabo en un contexto de "politización" de los movimientos femeninos, ya claves en la resistencia. Así pues, "ese algo se fue transformando en acción concreta, informal primero, concertada después" (Gaviola, Largo y Palestro, 1994, p.61). En efecto, las premisas de esta conciencia feminista se hicieron sentir cuando las mujeres, a menudo encarceladas en su país o en el exilio, empezaron a reflexionar sobre la dimensión sexista de la violencia y la tortura que sufrieron, tanto dentro del régimen militar como opositoras, como dentro de sus parejas (Hiner, 2015). Asimismo, los espacios abiertos por la Iglesia fueron muy propicios al entrecruce de experiencias íntimas. No obstante, aquellas reflexiones, si bien en esta época sí empezaron a cuestionar las relaciones de dominación entre hombres y mujeres, todavía no ponían en tela de juicio la metafísica de género que prescribía el régimen heteropatriarcal vigente, del que derivaban las identificaciones mujer/madre y sexo/ reproducción. Por lo tanto, las reivindicaciones aún no estaban orientadas hacia el derecho de la mujer a decidir sobre su cuerpo, el cual requería una desconstrucción de la corporeidad femenina.

En los años '80, junto a agrupamientos cada vez más masivos de mujeres, sobre todo de clase media o popular, investigadoras que se habían exiliado importaron a Chile el pensamiento feminista norteamericano y europeo, además de importantes herramientas conceptuales. El encuentro de las militantes y de estas retornadas ${ }^{5}$ favoreció el cuestionamiento de los roles tradicionalmente asignados a la mujer, así como la denuncia de la violencia estructural de género que padecían (Ríos Tobar, Godoy Catalán y Guerrero Caviedes, 2003; Kirkwood, 2010).

Paralelamente, en la misma época, se asiste a una derechización del sector hegemónico de la esfera eclesiástica, ${ }^{6}$ tras el nombramiento de Fresno como cardenal de la Iglesia Católica en 1983. Debido a sus 
posturas, mucho más conservadoras en el plano político que su predecesor, su elección como cardenal fue profundamente valorada por parte de la Junta, en el contexto de una crisis de legitimidad institucional que llevó al derrocamiento de la dictadura seis años después. De ahí se explica que las reacciones de la autoridad eclesiástica no tardaran en ser virulentas frente al cambio de paradigma interpretativo y el nacimiento de una conciencia de género por parte de las mujeres que, hasta la fecha, seguían impregnadas de un esencialismo en la praxis. Al respecto, Hiner dice que aquella postura del régimen autoritario traduce un "deseo de 'volver hacia atrás' y proteger 'los valores' hetero-patriarcales de Dios, familia y patria, ya que se buscaba 're-fundar' la nación a través de la 'buena crianza' de los niños dentro de la familia 'tradicional' y cristiana” (2015, p. 871). En este sentido, cuanto más crecían las demandas y críticas en contra de esta matriz de interpretación de las mujeres, más amenazada se sentía la Iglesia Católica en sus cimientos mismos.

La historia del Círculo de Estudios de la Mujer, creado en 1979, bajo el auspicio de la Academia de Humanismo Cristiano, es paradigmática de la degradación de las relaciones entre Iglesia y movimientos feministas en el sentido de que fue concebido al inicio como un espacio para fomentar las investigaciones de los intelectuales -víctimas de la dictadura- en torno a la condición de las mujeres chilenas. Sin embargo, fue disuelto y dividido en dos en 1983 por la Academia, pues sus actividades aglutinaban cada vez más mujeres (como las Jornadas de la Mujer o Movimiento Feminista impulsado por Julieta Kirkwood) y, sobre todo, sus análisis empezaron paulatinamente a sacar a luz la matriz heterosexual, patriarcal y violenta no sólo subyacente a la dictadura sino también al discurso clerical. ${ }^{7}$ Dicha matriz se encuentra reflejada en la Constitución de 1980.

A continuación, se profundizará en torno a los mecanismos teórico-pragmáticos de la Iglesia Católica en su intento por contrarrestar lo que a su juicio constituye una "desmoralización ciudadana", convirtiéndose así en un "contrincante acérrimo" (Lamas, 2012, p.42) del feminismo chileno.

\section{El "SECUlarismo estratégico" o los Planes de ACción de la Iglesia Católica PaRa CONTRARRESTAR LA AMPLIACIÓN DE LOS DERECHOS SEXUALES Y REPRODUCTIVOS (DDSSRR)}

La politización de lo privado y de la sexualidad, impulsada por las feministas de la segunda ola, encontró una traducción política internacional a partir de los años 70. Esta rápida llegada a la agenda internacional convirtió los temas denunciados por estas feministas bajo el prisma de una crítica general de los sesgos machistas y de la epistemología dominante que fomentaba los privilegios de raza y clase (Mosconi, 2008), en una de las principales líneas de intervención pública. Bajo el auspicio de las Naciones Unidas, se convocaron cuatro conferencias sobre la mujer cada cinco años, desde 1975 hasta 1995, a partir de las cuales se elaboraron planes de acción para promover el acceso de las mujeres al empleo, la educación y la salud. De ahora en adelante, el desarrollo y la paz eran inconcebibles sin la cooperación de las mujeres y se planteaba la vida en democracia bajo el prisma del género. Las chilenas participaron en todos estos encuentros, lo que les permitió dar una visibilidad internacional a las condiciones muy precarias en que estaban viviendo. A nivel latinoamericano, se organizó en Bogotá en 1981 el Primer Encuentro Feminista Latinoamericano y del Caribe, el cual propició la creación del 25 de noviembre como Día Internacional de la Eliminación de la Violencia contra la Mujer, que ahora es una fecha conmemorada internacionalmente.

En Chile, si bien este paso "de la anécdota a la categoría" como lo diría Celia Amorós (2008, p.15) se dio a partir de los años 80 , se materializó a inicios del restablecimiento de la democracia, por ejemplo con la creación del SERNAM en $1991 .^{8}$ Las demandas feministas, inicialmente enfocadas en las violencias intrafamiliares y las padecidas durante la dictadura, encontraron una respuesta política del Estado chileno (bajo el gobierno de Patricio Aylwin) a través de la creación de esta institución estatal, la cual tenía como objetivo fomentar la inclusión sociopolítica de las mujeres así como la igualdad de género. Sus políticas estaban marcadas por una apuesta por el consenso, al omitir deliberadamente de la agenda política temas como el aborto o el divorcio, que dividirían a la clase política, y que también se manifestaban en la elección 
voluntaria de una retórica diferencialista. Ésta se basa no tanto en los términos políticos operativos del feminismo de los 90, sino más bien en un discurso que no altera el rol social y cultural asignado a cada sexo en un determinado orden familiar, en un statu quo que refuerza el "sintagma mujer-familia" (Richard, 2008, p. 59). No obstante, esto no impidió que las políticas del SERNAM fueran fuertemente criticadas por los miembros de los partidos de derecha, Renovación Nacional $(\mathrm{RN})$ y la Unión Demócrata Independiente (UDI), allegados a la ideología conservadora heteropatriarcal de la antigua dictadura (Marques-Pereira, 2005). Aquella ideología fue igualmente compartida por la Iglesia Católica, la cual, en los primeros años de vuelta a la democracia, volvió a tejer cierta cercanía -no sólo ideológica- con estos partidos: "Paradójicamente la Iglesia empezó a formar alianzas con aquellas fuerzas políticas que apoyaron a la dictadura militar [...]. La Iglesia hizo uso de estas alianzas para discutir públicamente los 'temas nuevos', como por ejemplo el aborto, la educación sexual, el SIDA y sobre todo el tema del divorcio” (Veit Strassner, 2006, p.88).

La jerarquía, por medio de su declaración de noviembre de 1989, Certeza, coherencia y confianza. Un mensaje a los católicos en una hora de transición, ya hacía sentir sus temores frente a un régimen democrático que iba a dar espacio al nacimiento de nuevos marcos teórico-sociales en cuanto a la moral y la sexualidad. Efectivamente, las reivindicaciones no pararon de ampliarse a partir de los años 90 y sobre todo en la década del 2000. Aquellas, que tienen que ver con la autonomía del cuerpo de la mujer, el acceso e información a métodos anticonceptivos, el derecho a la no discriminación y las demandas en contra de la violencia sistémica de género o la brecha salarial, entre muchas otras (Morán Faúndes, 2013), están sustentadas por una retórica que, según la Iglesia Católica, radica en dos puntos: la "ideología del género" y la "cultura de la muerte" (Vaggione, 2017, p.12). Esta parrilla de lectura, conceptualizada respectivamente por los activistas católicos estadounidenses y por el propio Vaticano, revela la violencia discursiva y la voluntad de reactivar su hegemonía o autoridad moral, ya en declive.

Por una parte, el concepto de "ideología de género" denota un juicio despectivo, pues la palabra ideología remite socioculturalmente a la idea de una razón trastocada por un conjunto de creencias que buscan boicotear el predominio de la biología en la comprensión ontológica del sujeto. En concreto, la visión que el feminismo propone respecto al género - planteada sobre todo en la cuarta conferencia sobre la mujer de Pekín de 1995- socava radicalmente la concepción binarista y excluyente de los sexos biológicos que la Iglesia quiso reforzar al exponer su rechazo hacia el uso del término (Butler, 2016). Semejante interpretación biologicista, que supone la complementariedad de los sexos con fines reproductivos y familiares, se origina en una creencia irrestricta en la vida que debe ser garantizada desde la concepción hasta la muerte.

El caso del aborto es arquetípico de la oposición virulenta de la Iglesia al feminismo, por promover lo que denomina la "cultura de la muerte". Este concepto, acuñado por primera vez por Juan Pablo II y reapropiado por Benedicto XVI y Francisco, denuncia una concepción de la vida que se basa menos en su valor intrínseco que en su utilidad social, por lo que abarca una crítica global a la cultura del consumo y al relativismo. Refleja el dogma maniqueísta que presenta a la jerarquía como única institución garante de la vida frente a la inmoralidad de los paradigmas y militancias feministas, que suponen una suerte de profanación del derecho a la vida del que "está por nacer".

Efectivamente, aquella retórica feminista va subvirtiendo profundamente la moral eclesiástica y su antropología bíblica esencialista que presenta a la mujer como ser nutriente que dedica su vida "al despertar del otro" con una "ética del amor y la entrega" (Alfaro Álvarez, 2005, p. 109). Esta concepción naturalista de la mujer es compatible con la exaltación incondicional de la vida, claramente reivindicada en la encíclica Humanae Vitae de 1968: “[...] debemos una vez más declarar que hay que excluir absolutamente, como vía lícita para la regulación de los nacimientos, la interrupción directa del proceso generador ya iniciado, y sobre todo el aborto directamente querido y procurado" (Pablo VI, 1968, p. 17-18). Al concebir, la mujer se convierte en un mero objeto al que se le arrebata el ejercicio de su agencia e interferir en este proceso implicaría quebrantar la voluntad de Dios. Dicho esto, se entiende que la interpretación de la "ley moral natural" de la Iglesia Católica excluye intrínsecamente pensar la sexualidad y el género como resultados de un 
condicionamiento social: “[...] la identidad sexual es indiscutible, porque es la condición objetiva para formar una pareja en el matrimonio”?

De esta forma, los movimientos feministas, al cuestionar las relaciones de poder, las fronteras entre público y privado, además de afirmar la disociación entre sexualidad y reproducción, constituyen una verdadera amenaza en contra de este dogma moral y cultural. Es por ello que la jerarquía empezó, a inicios de los años 90, a establecer una serie de estrategias para disminuir, si no aniquilar, el impacto de aquellas demandas y lo que llamaría, más ampliamente, la "desmoralización ciudadana”, convirtiendo el cuerpo de la mujer en un terreno de disputa moral, social y jurídica. Para esta institución, la amenaza de la individualización que conllevaba la pérdida de referentes unificadores comunes (Costadoat, 2004) fue tal que tuvo que encontrar formas para retrasar la agenda estatal y la toma judicial de decisiones. Es una forma de intentar mantener su hegemonía cultural a escala global, sobre todo en el campo sexual, postura que se puede caracterizar como una "incapacidad de dialogar por su apego a un programa anti-género y pro-familia que reniega la posibilidad de hablar abiertamente de la sexualidad, la educación sexual y los derechos de la mujer" (Hiner, 2009, p.63). Para referirse a este conjunto de estrategias de bloqueo de los derechos sexuales y reproductivos, se suele usar el término "secularismo estratégico" (Vaggione, 2017, p.4). Este radica en tres puntos principales: la judicialización de los DDSSRR, el desplazamiento de su discurso a otras áreas y la ONGización.

La Iglesia Católica ha entendido temprano la importancia de inmiscuirse en el derecho, ya sea de manera explícita o implícita, con el fin de impedir la ampliación de los DDSSRR o, por lo menos, minimizar sus efectos (Vaggione, 2017). El derecho tiene tal poder performativo que ha sido históricamente uno de los medios más eficaces de legitimación y perpetuación de la dominación masculina y de los patrones heteronormativos. Aquellos son claramente compartidos por la Iglesia Católica, que tuvo cierto papel en la redacción de la Constitución de 1980. Este protagonismo es evidentemente implícito, pues recordemos que, en 1925, el Estado Chileno y el arzobispado de Santiago pactaron la separación entre el Estado y la Iglesia. ${ }^{10}$ Esto tiene su expresión en los primeros artículos de la Constitución que presentan a la familia como instancia reguladora de la sociedad y la afirmación del valor intrínseco del nasciturus: "La familia es el núcleo fundamental de la sociedad" (art.1), "La ley protege la vida del que está por nacer" (art. 19.1). Pese a su aparente neutralidad, tales artículos en la práctica se encuentran cargados de una ideología patriarcal y cristiana, por lo que cabe diferenciar "el nivel locucionario e ilocucionario" de la ley (Valenzuela Oyaneder y Villavicencio Miranda, 2014, p. 274).

Los funcionarios y políticos de confesión católica, a través de distintos mecanismos, han podido ejercer su influencia en el derecho, ya sea en la interpretación de leyes vigentes o en la elaboración de nuevas. Esto en la práctica se traduce en su oposición categórica o apoyo a tentativas para que no se apruebe una ley, por ejemplo, recurriendo a la instancia del Tribunal Constitucional (Vaggione, 2017). Lo más arduo es discernir esta influencia cuando la argumentación del funcionario no está apoyada por documentos eclesiásticos o referencias directas a los Textos Sagrados, lo cual ocurre cada vez más hoy en día. En efecto, la segunda gran estrategia de la Iglesia Católica fue el desplazamiento de su discurso religioso a otras áreas, tales como la biomedicina o la psicología, pues son consideradas más legítimas en la medida en que supuestamente no se basan en convicciones personales o religiosas (Vaggione, 2017). De esta forma, por medio de argumentos de "ciencias", la Iglesia lucha contra la "ideología de género" y la "cultura de la muerte", reafirmando su comprensión de la familia, la homosexualidad, el vínculo matrimonial, el valor del feto etc. (Galaz Valderrama, Sepúlveda Galeas, Poblete Melis, Troncoso Pérez, y Morrison, 2018). Dicha oposición adquiere fuerza en virtud de su cruce y ramificación con otros sectores seculares, socialmente legitimados.

Por último, a partir de los años 80 , se observa dentro de la sociedad civil la emergencia de muchas ONGs “pro-vida” (Peñas Defago y Morán Faúndes, 2015), que afirman que hay que proteger la vida del ser humano desde su concepción hasta su muerte. Aquellas se concentran sobre todo en luchar contra la despenalización del aborto, el acceso a la píldora del día después, el uso ciertos métodos anticonceptivos y la educación sexual en las escuelas. Podemos mencionar la Red por la Vida y la Familia, Fundación Chile Unido o Siempre por 
la Vida, así como ciertas organizaciones vinculadas a universidades privadas católicas, tales como el Instituto de Ciencia de la Familia Universidad de Los Andes (cuyo rector es prelado del Opus Dei) o el Hospital Universitario de la Pontificia Universidad Católica de Chile que se niega a realizar “abortos", incluso en caso de urgencia vital. Esta profusión de ONGs también revela el deslizamiento de lo religioso hacia lo secular, tanto en sus formas de militancia como en sus argumentos en sí. Estos últimos no proceden siempre de fuentes religiosas, pero sí apelan de manera sistemática a las nociones de tradición y familia por medio de una retórica excluyente del activismo feminista y LGBTQI+ (Peñas Defago y Morán Faúndes, 2015). ${ }^{12}$ Tales grupos, en este sentido, se posicionarían "en contra de" la vida y la familia. Así pues, el concepto de “activismo heteropatriarcal”, acuñado por Morán Faúndes (2018), pone énfasis en la imbricación compleja - más que dicotomía- entre lo secular y lo religioso, así como en la pluralidad de las organizaciones que a veces únicamente se trata de actores aislados (bioeticistas, abogados, etc.). El factor convergente de estos actores es menos la creencia común en una religión dada que convicciones ético-morales plurales cristalizadas a menudo en torno al concepto de "defensa de", que remite a un orden social y sexual que hay conservar a toda costa frente a lo que podría abarcar la amenaza del "relativismo".

Este secularismo estratégico, marcado por la heterogeneidad de sus actores y una retórica a menudo laica, fue bastante eficaz. En efecto, muchas leyes fueron declaradas “inconstitucionales" por la presión de la derecha conservadora y las ONGs. Podemos agregar que su influencia es todavía hoy clara en la elección de ciertos términos "paragua" usados en el derecho y las organizaciones públicas que tienen un efecto despolitizador. A modo de ejemplos, los términos 'diversidad sexual' o 'violencia intrafamiliar' (Galaz Valderrama, Sepúlveda Galeas, Poblete Melis, Troncoso Pérez, y Morrison, 2018) suponen cierta configuración del poder social. ${ }^{13}$ El caso de la despenalización penosa y tardía del aborto terapéutico en 2017 es significativo del éxito de la Iglesia Católica en obturar los DDSSRR.

\section{LOS RETOS DE LA DESPENALIZACIÓN PARCIAL DEL ABORTO: PROMULGACIÓN BAJO CONDICIONES Y APLICACIÓN ESTORBADA}

A inicios del siglo XX, el tema del aborto se cristaliza en Chile como una problemática de salud pública. A diferencia de los países europeos, el sector de la salud del país tardó mucho tiempo en publicar investigaciones y reportes sobre el asunto. Frente a las facilidades de proceder a un aborto clandestino y al aumento de las mujeres que acudían al hospital por complicaciones post-aborto, los médicos chilenos empezaron a denunciar con virulencia los excesos de abortos "criminales", acusando primero a las matronas que aceptaban realizar abortos a bajo costo (Campo Peirano, 2008, p.135). Ellos asociaban esta práctica que llamaban "aborto clandestino" o "esterilidad voluntaria"-, por una parte, a una amenaza a la patria y, por otra, un hábito peligroso que se había masificado, pues implicaba un control de las mujeres sobre su propio cuerpo. En este sentido, su política de represión, castigo y exclusión de las mujeres, más que un problema de orden sanitario, era sumamente político, además de apoyarse en una retórica muy conservadora y machista.

Sin embargo, en un contexto de alta mortalidad materna causada por abortos, ya sea por escasez de recursos económicos o infecciones puerperales (Allende, 1939), se legalizó finalmente en 1931 el aborto terapéutico, hasta la fecha considerado como un delito. ${ }^{14}$ En ese entonces estaba autorizado en tres causales: el riesgo de muerte de la madre, la inviabilidad fetal o si el embarazo era producto de una violación. ${ }^{15}$ Pese a su legalidad, estaba muy mal visto y aún más a partir de 1973. En efecto, la dictadura militar tenía una postura anti-aborto y pro-natalista muy firme, aunque su prohibición constitucional no fue ratificada: "No se llevará a cabo ninguna acción en la que el objetivo sea provocar un aborto" (Lidia Casas, 2019, p.123). ${ }^{16}$ En este sentido, esto refleja el afán del Estado por controlar el cuerpo de las mujeres y reprimir cualquier intento de emancipación.

Bajo la iniciativa de Jorge Medina, obispo católico y de José Toribio Merino, almirante y miembro de la Junta Militar, se restauró en 1989 la prohibición total del aborto (Ley n¹8.826). Durante la transición 
democrática, la cultura del compromiso y de lo políticamente correcto por parte de la nueva coalición de poder (la Concertación de Partidos por la Democracia), la disipación de la lucha feminista, y los enclaves autoritarios (las leyes de amarre) constituyeron varios factores que explicaron que la ampliación de los DDSSRR tardara en llegar hasta la agenda política. Más tarde, entre 2000 y 2012, miembros del Partido por la Democracia (PPD) y del Partido Socialista (PS) presentaron 12 boletines para intentar volver a legalizar el aborto terapéutico (Lidia Casas, 2019, p.124), pero todos fueron rechazados por la Democracia Cristiana (DC), Renovación Nacional (RN) y la Unión Demócrata Independiente (UDI).

Esto cambió paulatinamente con la llegada al poder de Ricardo Lagos (2000-2006) y Michelle Bachelet (primer mandato 2006-2010), pues ambos tenían la intención de ya no ceder a la presión de la derecha, gran aliada de la Iglesia Católica, además de atreverse a debatir sobre temas que generaban tensiones dentro de su alianza política, la Concertación. Aquella alianza, disuelta en el año 2010, cuyo afán era "sujetar los desarreglos de lo social" (Richard, 2002, p.3), estaba conformada por el bloque político de resistencia contra la dictadura que ganó en el plebiscito, el cual iba a marcar el fin del autoritarismo en Chile. Agrupaba a varios partidos, ubicados en la izquierda y centro del espectro político, entre otros, la Democracia Cristiana (DC). La primera década de la vuelta a la democracia, en la que presidió dos veces seguidas, con Patricio Aylwin (1990-1994) y Eduardo Frei (1994-2000), la política estatal estuvo marcada por una omisión de las demandas ciudadanas (Dávila y Fuentes, 2003) y en particular las demandas feministas, ideológicamente más cercanas a la izquierda del PS y al partido comunista. En el plano socio-moral, los grupos más conservadores de la DC tendían a votar más con la derecha, por lo que las reformas en torno a los derechos de las mujeres se promulgaron con mucha dificultad. Prueba de esto es la tardía legalización del divorcio en 2004 (Ley del Matrimonio Civil, n¹9.947) bajo el gobierno de Ricardo Lagos (PPD), que causó mucha tensión tanto dentro de su partido mismo como dentro de la coalición política. ${ }^{17}$ Asimismo, los campos de acción del SERNAM en la primera década, cuyos dos dirigentes eran demócratas cristianas, también evidencian esta voluntad de promulgar leyes vaciadas de su alcance feminista y centradas más en políticas paliativas (violencia intrafamiliar, capacitación laboral y ayuda a los hogares monoparentales femeninos con el programa Mujeres Jefas de Hogar) y no tanto en políticas estructurales que den cuenta de la raíz de la violencia patriarcal (Marques-Pereira, 2005). Es decir, en la práctica esto supuso que el SERNAM fuera una institución que no cuestionara las categorías de género y sexualidad, salvaguardando el estatus quo de la familia y la ideología sexual dominante.

En el caso del aborto, el punto de inflexión se sitúa cuando Bachelet en su cuenta pública instala este candente tema de nuevo en la agenda política al anunciar su voluntad de despenalizar el aborto terapéutico. La expresidenta, junto a la organización La Mesa por la Vida y la Salud de las Mujeres, con que elaboró su estrategia, sabía que plantear de entrada una despenalización total del aborto no iba a ser factible. Es por ello que decidió restringirse a las tres causales ya presentes en la ley de 1931, sabiendo que el debate iba a dirigirse más en la protección de la vida que la libertad de la mujer (Lidia Casas, 2019). Ahí empieza un debate enardecido, que acabará con la promulgación de la ley 21.030 de despenalización del aborto en tres causales en septiembre de 2017, al cabo de vaivenes interminables entre el Senado y la Cámara de Diputados. Esta lentitud en la toma de decisiones no sólo releva la fragmentación de la política en Chile, sino que también y, sobre todo, la interferencia aún muy considerable de la Iglesia Católica en la promulgación de leyes que atentan directamente contra su doctrina moral.

Primero, la Constitución de 1980, cuyos redactores, como hemos mencionado anteriormente, eran directamente o no vinculados a la Iglesia Católica, fue pensada de modo que las reformas con capacidad de transformación social pudieran ser difícilmente promulgadas. En nuestro caso, los altos quórums en las Cámaras permitieron que la derecha pudiera ejercer su poder de veto y, de esta forma, impedir o retrasar la aprobación de varias leyes. Asimismo, el Tribunal Constitucional - cuyos ministros suplentes son todos de derecha hasta incluso vinculados anteriormente a la Universidad de Los Andes, basada en la doctrina Opus Dei, o al movimiento gremialista fundado por Jaime Guzmán - consideró varias veces leyes como 
inconstitucionales, por ejemplo, la ley de penalización al negacionismo presentada en noviembre de 2020 o la del reconocimiento del 'matrimonio igualitario' en junio de 2020. En 2008, sobre la autorización de la anticoncepción de emergencia dijo que el nasciturus "e[ra] persona desde la concepción [de manera que] (...) el aborto es siempre inconstitucional, sin hacerse ninguna otra pregunta ni detenerse en ninguna otra consideración" (Valenzuela Oyaneder y Villavicencio Miranda, 2014, p. 295). En el caso de la despenalización del aborto terapéutico, Chile Vamos, coalición de partidos de derecha neoliberales y ultraconservadores, presentó dos requerimientos ante el Tribunal Constitucional, esgrimiendo que contradice el derecho a la vida consagrado en el artículo 19.1 de la Constitución. En definitiva, la aplicación de la ley está sustentada en una retórica pro-vida que se traduce en la negación del derecho de la mujer a decidir sobre su cuerpo y, por lo tanto, en la pérdida de su agencia.

Esta postura pro-vida requiere de la identificación de la mujer con la maternidad. En este sentido, el aborto representa un peligro en la medida en que, al introducir el control de la mujer sobre su capacidad reproductiva, contempla la posibilidad del ejercicio de una sexualidad más amplia que considera el placer femenino. Precisamente, lo que está en juego, y causa tanto tormento a la Iglesia Católica, es que el aborto cuestiona su mito de la mujer-madre cuyo destino es "transmitir la vida" dentro del marco de la relación conyugal (Pablo VI, 1968, p.16-17). Para el activismo feminista, esta doctrina es anti-democrática, pues va en contra de los principios fundamentales que pretenden garantizar la capacidad de individuación y deliberación del sujeto, cualquiera sea el género. Este tipo de argumento dogmático abstracto y ahistórico, que remite a la antropología bíblica, oculta todos los problemas sociales subyacentes causados por la imposibilidad de interrupción del embarazo: precariedad de las familias monoparentales, riesgo de muerte en los abortos clandestinos, imposibilidad para las mujeres sin recursos económicos de abortar, embarazo forzado dentro de una relación abusiva y violenta, etc. Entonces, cabría preguntarse, ¿cómo es posible que se haya aprobado dicha ley frente a una interferencia tan potente de los conservadores?

Es cierto que fue una derrota para dichos actores conservadores, sin embargo, tampoco fue una victoria tan jubilosa para las feministas. En efecto, si analizamos las causales, ninguna está asociada a la autonomía de la mujer: la decisión del aborto está a manos del cuerpo médico. La terminología elegida fue determinante en la aprobación de la ley en la medida en que la cuestión del aborto, que remitía directamente a la elección de la mujer sobre si quería estar embarazada o no (y todas las consecuencias que traía consigo tal decisión), fue neutralizada por consideraciones puramente técnicas e higiénicas. Este desplazamiento tecnicista podría ser visto como una manera de disminuir los efectos de esta medida progresista.

Desde la presentación del boletín hasta la aprobación de la ley, muchas enmiendas más restrictivas por parte de la derecha se hicieron en cuanto a la privacidad del proceso del aborto, los plazos y, sobre todo, la objeción de conciencia. El caso de la promulgación con condiciones muy estrictas es paradigmático del hecho de que, en este país, la ampliación de los DDSSRR se ha visto siempre obstaculizada en su aplicación. De hecho, antes de que se haya promulgado la despenalización del aborto, el tema ya había sido revisitado por sectores de la UDI y RN que buscaban endurecer las penas para las mujeres que lo practicaran (MarquesPereira, 2005). Insólitamente esta intención se concretó en la ley del 2017. A modo de ejemplo, si una mujer o niña aborta por uno de los tres motivos, el hospital o médico debe avisar a la Fiscalía para proceder a una investigación penal. Además, en el caso de una violación, los plazos se redujeron de 18 a 14 semanas para las niñas menores de 14 años para abortar, lo cual es muy problemático considerando el trauma que implica tal evento y el estado de sideración que paraliza a la víctima durante días si no años (Lidia Casas, 2019).

Estas condiciones, negociadas por la derecha conservadora, revelan lo estigmatizante e inquisidora que es la ley respecto a las mujeres, sobre todo cuando se trata de una violación. Sin embargo, su mayor logro fue, sin duda, conseguir que no se prohibiera la cláusula de conciencia por medio de un requerimiento ante el Tribunal Constitucional que históricamente la declaró inconstitucional. Gracias a la objeción de conciencia, médicos y hospitales pueden decidir no realizar abortos en ningún caso y hasta pueden atreverse a no proporcionar la información necesaria a las mujeres, denunciar a una mujer que consulta por complicaciones 
de un aborto ilegal, maltratarla ${ }^{18}$ o simplemente no acceder a atenderlas en su consulta. ${ }^{19} \mathrm{Si}$ bien la Iglesia en cuanto institución no se encuentra presente en la relación médico paciente aquí, su discurso, alimentado tras décadas de influencia socio-política en Chile, todavía tiene un impacto en el trato que el especialista da a su paciente, en las negativas a tratarla o en los gestos de desprecio a su situación y género. ${ }^{20}$

A pesar de que esta ley restrictiva y que el estigma social siga vigente, Chile ha experimentado un detonante político que podría derrocar o, al menos, estremecer la influencia histórica de la Iglesia Católica en la política estatal. Tras la aprobación masiva de lxs chilenxs de un proceso constituyente para cambiar la Constitución el 25 de octubre de 2020, se eligió, en mayo de 2021, a 155 convencionales constituyentes que se encargarán de redactar la nueva Carta Magna. Además de ser la primera Constitución paritaria del mundo, cabe destacar que dentro de lxs constituyentes electxs, los partidos tradicionales, entre los cuales la UDI, la DC y RN, no constituyen ni la mitad de la Asamblea Constituyente. Por este motivo, a partir de las condiciones actuales de la Convención Constituyente, se da pie para que los partidos más conservadores y ligados a la jerarquía en el plano ideológico pierdan su representatividad histórica. Esto puede conllevar un giro valórico notorio con respecto a los derechos de las mujeres, así como de las disidencias sexuales o los pueblos originarios.

\section{A MODO DE CONCLUSIÓN}

La influencia que ha ejercido históricamente la Iglesia Católica en Chile sobre las políticas del Estado y el funcionamiento de la sociedad ha adoptado nuevas formas desde hace tres décadas. Cuando su doctrina, llevada por líderes políticos conservadores, no se manifiesta en una serie de argumentos seculares de ciencia dura, es llevada con orgullo por ONG pro-vida que se entregan en cuerpo y alma a la lucha contra la expansión de los DDSSRR. Su fuerza hoy radica en que su discurso se diseminó y tiene resonancia en ciertos sectores de la sociedad no especialmente católicos. En este sentido, la Iglesia Católica representa uno de los mayores, si no es el primer enemigo de los movimientos feministas, con quienes no ha tenido siempre tantos litigios. El ejemplo de la despenalización del aborto en 2017 es muy revelador de esta tensión y de la inclinación profundamente conservadora de la clase dirigente. Se hace todo lo posible para disuadir a las mujeres de abortar, no sólo legalmente con las condiciones extremadamente estrictas y poco empáticas en la ley del aborto de 2017, sino también socialmente a través de la exclusión y la discriminación a las que están expuestas. La brecha entre la promulgación de leyes sobre los DDSSRR y su aplicación concreta parece socavar las pretensiones de mejora de la vida de las mujeres y disidencias sexuales por medio de la vía jurídica. En este sentido, cabría preguntarse qué tan eficaz resulta esta vía al momento de garantizar estos derechos, esto es, si en este acto de regulación legal en condiciones restrictivas acaso no se reproduce o legitima el dispositivo de subjetivación heteropatriarcal.

\section{REFERENCIAS}

Alfaro Alvárez, J. (2005). La retórica del poder. Miradas respecto del feminismo, las mujeres y lo social. Análisis del discurso de la Iglesia Católica. Athenea Digital, 7, 105-113.

Allende Gossens, S. (1939). La realidad médico-social chilena. Santiago: Ministerio de Salubridad.

Amorós, C. (2008): Conceptualizar es politizar. En: Patricia Laurenzo et al. (coords.): Género, violencia y derecho (pp. 15-25). Valencia: Tirant lo Blanch.

Araya Espinoza, A. (2008). Un imaginario para la mezcla. Mujeres, cuerpo y sociedad colonial. En S. Montecino, Mujeres chilenas. Fragmentos de una historia (pp. 33-40). Santiago: Catalonia.

Barrios Valdés, M. (1992). Chile y su Iglesia: una sola historia. Santiago: Ediciones Salesiana.

Butler, J. (2016 [2004]). Deshacer el género. Barcelona: Ediciones Paidós. 
Campo Peirano, A. (2008). La nación en peligro: el debate médico sobre el aborto en Chile en la década de 1930. En M. S. Zárate Campos (Comp.). Por la salud del cuerpo. Historia y politicas sanitarias en Chile. Santiago: Ediciones Universidad Alberto Hurtado.

Cabrera Gómez, M. J. y Errázuriz Tagle, J. (2015). Historia, mujeres y género en Chile: la irrupción de las autoras femeninas en las revistas académicas. Los casos de revista Historia y Cuadernos de Historia. Historia (Santiago), 48(1), 279-299.

Censo de Población y Vivienda: Instituto Nacional de Estadísticas. (2012). Censo de Población y Vivienda.

Código Sanitario de Chile. 31 de enero de 1968 (Chile).

Código Penal de la República de Chile. 1 de marzo de 1875 (Chile).

Constitución Política de la República de Chile de 1980.21 de octubre de 1980 (Chile).

Coogan, Michael, ed. (2007). La Nueva Biblia Anotada de Oxford. Oxford: Oxford University Press.

Costadoat, J. (2004). El catolicismo ante la individualización. Teología y vida, 45(4), 605-610. https://dx.doi.org/10 $.4067 /$ S0049-34492004000400006

Cruz Contreras, M. A. y Ramírez, C. (2015). Memorias subalternas sobre la Dictadura Militar en Chile. El caso de la corriente liberadora de la Iglesia Católica. Archives de sciences sociales des religions, 170, 17-35.

Dávila, M. y Fuentes, C. (2003). Promesas de cambio. Izquierda y derecha en el Chile contemporáneo. Santiago: Editorial Universitaria S. A.

Del Picó Rubio, J. (2019). El lugar de la religión en el Estado laico: el modelo de laicidad en Chile dos décadas después de la entrada en vigor de la Ley $N^{\circ}$ 19.638. Revista de derecho26(1). http://dx.doi.org/10.22199/issn.0718-97 53-2019-0001

Erra\#zuriz Tagle, J. (2005). Discursos en torno al sufragio femenino en Chile 1865-1949. Historia (Santiago), 38(2), 257-286.

Galaz Valderrama, C., Sepúlveda Galeas, M., Poblete Melis, R., Troncoso Pérez, L. y Morrison Jara, R. (2018). Derechos LGTBI en Chile: tensiones en la constitución de otredades sexualizadas. Psicoperspectivas, 17(1), 6-16. https://doi.org/10.5027/psicoperspectivas-vol17-issue1-fulltext-1165

Gaviola, E., Largo, E., y Palestro, S. (1994). Una historia necesaria. Mujeres en Chile: 1973-1990. Santiago de Chile: Aki\# \& Aora.

Gómez Urrutia, V. (2012). Divórcio à la chilena: família, gênero e cidadania no Chile, 1990-2004. Revista de Sociologia e Politica (Curitiba), 20(44), 177-195.

Gutiérrez, G. (1972). Teología de la Liberación. Perspectivas. Salamanca: Ediciones Sígueme.

Hiner, H. (2009). Voces soterradas, violencias ignoradas: discurso, violencia política y género en los informes Rettig y Valech. Latin American Research Review, 44(3), 50-74.

Hiner, H. (2015). "Fue bonita la solidaridad entre mujeres": género, resistencia, y prisión política en Chile durante la dictadura. Revista Estudos Feministas, 23(3), 867-892. https://dx.doi.org/10.1590/0104-026X2015v23n3p867

Juan Pablo II. (1995). Evangelium Vitae (Carta encíclica).

Kirkwood, J. (2010) [1986]. Ser política en Chile. Las feministas y los partidos. Santiago de Chile: FLASCO.

Lamas, M. (2012). Mujeres, aborto e Iglesia Católica. Revista de El Colegio de San Luis. 3(3), 42-67.

Lidia Casas, G. M. (2019). Abortion in Chile: The Long Road to Legalization and its Slow Implementation. Harvard School of Public Health, 21(2), 121-132.

Madrid Ramírez, R. (2018). Razones sistemáticas, más un argumento teórico, para rechazar la constitucionalidad del proyecto de aborto en tres causales en Chile. Revista de derecho chileno, 45(1), 255-268. http://www.dx.doi.or g/10.4067/S0718-34372018000100255

Marques-Pereira, B. (2005) “Le Chili: Les femmes et la gauche. Une relation amicale?". Revue internationale de politique comparée, 12(3), 365-378. 
Ministerio de Salud (2017). Informe sobre Brechas del Personal de Salud por Servicio de Salud. Recuperado de: https://www.minsal.cl/wp-content/uploads/2015/08/Informe-Brechas-RHS-en-Sector-P\%C3\%BAblico _Abril2017.pdf

Mosconi, N. (2008). Mai 68 : le féminisme de la « deuxième vague » et l'analyse du sexisme en éducation. Les Sciences de l'éducation - Pour l'Ère nouvelle, 3(3), 117-140. https://doi.org/10.3917/lsdle.413.0117

Morán Fau\#ndes, J. M. (2013). Feminismo, Iglesia Católica y derechos sexuales y reproductivos en el Chile postdictatorial. Revista Estudos Feministas, 21(2), 485-508. http://dx.doi.org/10.1590/S0104-026X20130002000 04

Morán Faúndes, J. M. (2018). Religión, secularidad y activismo heteropatriarcal: ¿qué sabemos del activismo opositor a los derechos sexuales y reproductivos en Latinoamérica? La ventana.Revista de estudios de género, 5(47), 97-138.

Pablo VI. (1968) [1983]. Humanae Vitae, sobre la regulación de la natalidad. Santiago de Chile: Ediciones Paulinas.

Pacheco Gómez, Máximo (2012). Rol del Cardenal Raúl Silva Henríquez. Golpe militar en Chile. Sus Te Deum durante la dictadura. Santiago de Chile: Ediciones Copygraph.

Peñas Defago, M. A. y Morán Faúndes, J. M. (2015). Nuevas configuraciones religiosas/seculares: las ONG "pro-vida" en las disputas por las políticas sexuales en Argentina. Religia\# o e Sociedade, 35(2), 340-362. http://dx.doi.org /10.1590/0100-85872015v35n2cap14

Pontificio Consejo Justicia y Paz. (2004). Compendio de la Doctrina Social. Recuperado de: https://www.cristianism eijusticia.net/sites/default/files/Economia/compendio-dsi.pdf

Power, M. (2009). Poder Femenino. En Power, M., La mujer de derecha: el poder femenino y la lucha contra Salvador Allende, 1964-1973 (pp.193-215). Santiago: Centro de Investigaciones Diego Barros Arana.

Richard, N. (2002). La problemática del feminismo en los años de transición en Chile. En Mato, D. (Comp.). Estudios Latinoamericanos sobre cultura y transformaciones sociales en tiempos de globalización (pp. 227-239). Buenos Aires: CLASCO.

Richard, N. (2008). Feminismo, género y diferencia(s). Santiago: Editorial Palinodia.

Ríos Tobar, M., Godoy Catalán, L. y Guerrero Caviedes, E. (2003). ¿Un nuevo silencio feminista? La transformación de un movimiento social en el Chile postdictadura. Santiago: Editorial Cuarto Propio.

Sánchez Gaete, M. (2009). Historia de la Iglesia en Chile. Tomo I. En los caminos de la conquista espiritual. Santiago: Editorial Universitaria de Chile.

Sánchez Gaete, M. (2014). Historia de la Iglesia en Chile. Tomo IV. Una sociedad en cambio. Santiago: Editorial Universitaria de Chile.

Vaggione, J. M. (2017). La Iglesia Católica frente a la política sexual: la configuración de una ciudadanía religiosa. Cadernos Pagu, 50. https://doi.org/10.1590/18094449201700500002

Valenzuela Oyaneder, C. y Villavicencio Miranda, L. (2014). La constitucionalidad de los derechos sexuales y reproductivos. Hacia una igual ciudadanía para las mujeres. Revista Ius et Praxis 21(1), 271-314. https://dx.do i.org/10.4067/S0718-00122015000100008

Veit Strassner, M. A. (2006). La Iglesia Chilena de 1973 a 1993: de buenos samaritanos, antiguos contrayentes y nuevos aliados. Un análisis politológico. Teología y vida, 47(1), 76-94.

Zamorano Varea, P. (2008). "Ganarse la vida” en la Colonia. Mujeres y Oficios. En Montecino Aguirre, S. (Comp.) Mujeres chilenas. Fragmentos de una historia. Santiago de Chile: Catalonia.

\section{Notas}

1 A pesar de esta disminución, que se puede vincular con el simultáneo auge del ateísmo y del evangelismo, todavía más de la mitad de lxs chilenxs se declara de fe católica. El censo nacional más reciente realizado por el Instituto Nacional de Estadísticas fue publicado en 2017. Sin embargo, se redujeron a la mitad el número de preguntas en comparación con los censos anteriores, excluyendo en particular las preguntas relacionadas con la confesionalidad. A la pregunta "¿Cuál es su religión o credo?”, del censo anterior publicado en 2012, 67\% de lxs chilenxs de más de 15 años declararon ser de confesión católica (Censo de Población y Vivienda, INE, 2012). Cabe mencionar también la encuesta, más reciente, 
realizada por el Centro de Estudios Públicos, que mostraba que, en 2018, 55\% de lxs chilenxs se declararon católicxs. Siendo las metodologías de ambos institutos muy diferentes, sólo podemos concluir que la religión católica es todavía muy predominante en Chile.

2 Ministerio de Salud (abril 2017). Informe sobre Brechas del Personal de Salud por Servicio de Salud. Recuperado de https://www.minsal.cl/wp-content/uploads/2015/08/Informe-Brechas-RHS-en-Sector-P\%C3\%BAblico_Abril2 017.pdf, pp. 20-21.

3 Coogan, Michael, ed. (2007). La Nueva Biblia Anotada de Oxford. Oxford: Oxford University Press, Proverbios 31:10-31.

4 Esta irrupción en el ámbito público no implicaba necesariamente una reivindicación de su papel político. Si bien algunas activistas, a menudo ubicadas en la izquierda del espectro político, reivindicaban su lucha como abiertamente política, como fue el caso de las miristas, otras negaron rotundamente esta etiqueta. Es más, en aquellos años, la relación de las mujeres con la política es sintomática de la tensión entre el cumplimiento de su rol como dueña de casa y madre ejemplar y su voluntad de integrarse al espacio político. Al respecto, Gaviola, Largo y Palestro sostienen: "Era pedirles demasiado sumar una militancia política o gremial a su ser madre-esposa-dueña de casa-trabajadora” (1994, p.24). A modo de ejemplo, es relevante mencionar el caso del movimiento anti-allendista Poder Femenino. Si bien sus fundadoras, Elena Larraín y María Correa Morandé, eran mujeres que ya habían participado en otros movimientos políticos antes y tenían vínculos estrechos con los partidos de oposición a la Unidad Popular, Poder Femenino nunca se presentó como un movimiento propiamente político. La dificultad en la elección de un nombre para su partido demuestra la voluntad de sus integrantes de integrarse en la escena pública sin allanar la escena "política" que, según ella, pertenecía a los varones. De esta forma, el nombre "Poder Femenino" da a ver la ambigüedad del movimiento que quería influir en la escena política y a la vez cumplir con su rol de género a través de con una comprensión esencialista de éste. Véase Power, M. (2009).

5 "Surge la cuestión de género, es decir, resurge, reaparece, se devela, decía Julieta Kirkwood, la cuestión es que trabajamos comenzamos a elaborar lo que ya estaba elaborado, a inventar lo inventado. De esto nos daríamos cuenta a la llegada de las primeras retornadas del exilio y también en los Encuentros Feministas Latinoamericanos. Es que estas cosas, como todas las revoluciones, tienen que salir de las profundidades de las negaciones mismas..." (Gaviola, Largo y Palestro, 1994, p. 96)

6 Nombrado por el Papa Juan XXIII en 1961, el cardenal Silva Henríquez, que encarnaba los ideales socialistas, ya no fue autorizado para ejercer su función cuando llegó Juan Pablo II. Silva Henríquez fue reemplazado en 1983 por el arzobispo de La Serena, el cardenal Fresno Larraín (Barrios Valdés, 1992). Mientras que, por una parte, Silva Henríquez -en su declaración pronunciada unos días después del golpe militar- oscila entre un apoyo reservado al régimen y la desesperación por la dramática situación que estaba gestándose, por otra, Fresno expresa su apoyo a los militares de manera explícita (Veit Strassner, 2006).

7 "Porque todo estaba perfecto mientras hiciéramos trabajo contra la dictadura, dice E., pero cuando empezamos a criticar la familia y a hablar de relaciones sexuales, de divorcio, de aborto, y empezó a salir el boletín donde aparecían estos temas, en la Academia tuvieron una reunión y, bueno, el Círculo para afuera... la Iglesia era progresista en la cuestión de los Derechos Humanos, pero en estas cuestiones era conservadora como siempre" (Gaviola, Largo y Palestro, 1994, p.128-129).

8 El Servicio Nacional a la Mujer (SERNAM) fue renombrado en 2016 Servicio Nacional a la Mujer y la Equidad de Género (SERNAMEG) Véase Marques-Pereira, 2005.

9 Pontificio Consejo Justicia y Paz. (2004). Compendio de la Doctrina Social. Disponible en: https://www.cristianismeij usticia.net/sites/default/files/Economia/compendio-dsi.pdf, \$224.

10 Sin embargo, esta aconfesionalidad nunca ha sido respetada realmente cuando vemos la diferencia de trato del Estado chileno entre los diferentes credos. Para más detalles ver Del Picó Rubio, 2019. Ahora, en cuanto a la influencia de la autoridad eclesiástica en la redacción de 1980, podríamos postular que fue por medio de sus redactores, conservadores católicos, a pesar de que ningún dato objetivo lo pueda corroborar.

11 El término nasciturus fue inventado simultáneamente a la emergencia de las demandas feministas a favor de la ampliación de los DDSSRR por el Vaticano. Es utilizado tanto por la jerarquía clerical como por las organizaciones "pro-vida” para resaltar el carácter ya viviente del feto. Asimismo, el uso del latín presenta a dicha institución como garante del dominio moral.

12 Los grupos que sí se apoyan en fuentes religiosas aplican al cigoto la máxima latina infans conceptus pro iam nato habetur. En el derecho romano significa que "al concebido se le trata como nacido para todo aquello que le favorezca". Se trata de un principio al que recurren ciertas organizaciones pro-vida, además de la Suma teológica de Tomás de Aquino. Véase Madrid Ramírez, 2018.

13 Primero, el término 'diversidad sexual' no permite entender por qué las categorías de la sexualidad y de géneros vigentes son prescriptivas de ciertas relaciones de poder, donde lo dominante culturalmente es la matriz heterosexual (expresión acuñada por Butler). En este sentido, el concepto de 'diversidad' no cuestiona esta matriz dominante, sino que la legitima y ratifica. El concepto de 'disidencia sexual', en cambio, sí da cuenta de relaciones de poder en que los disidentes o queer quedan fuera, al margen, de esa criba de inteligibilidad. En cuanto al segundo ejemplo, el de 'violencia intrafamiliar', no 
permite dar cuenta de que se trata de una violencia patriarcal ejercida específicamente hacia las mujeres y en todos los planos sociales. El adjetivo remite a una retórica de las "violencias privadas" que invisibiliza la dimensión estructural y sistemática de la violencia de género.

14 Código Penal de la República de Chile. 1 de marzo de 1875 (Chile), art. 342 a 345.

15 Código Sanitario de Chile. 31 de enero de 1968 (Chile), art. 119.

16 Traducción propia del original: "No action will be taken in which the aim is to cause an abortion."

17 Se trata de una ley impulsada por un grupo de diputados de la DC a partir del año 1995. El presidente del mismo partido en aquel entonces, Ricardo Krauss, era fuertemente en contra de esta ley, pues veía en ella una forma de legitimar una pluralidad de "familias" y un factor de desintegración social, amenazando de esta forma la estabilidad de la familia nuclear heteronormada en Chile. Véase Gómez Urrutia, 2012.

18 "They show them the scan and ultrasound forcing women to look at it, or they talk about god or things like that." (Lidia Casas, 2019, p.126).

19 "That patient does not exist for me, I'm an objector" (Lidia Casas, 2019, p.126).

20 En este caso se puede tomar el ejemplo del hospital universitario de la PUC. Para entender a cabalidad la complejidad de esta decisión, cabe recordar que, para esta institución, existe, desde el punto de vista médico y ético, una diferencia entre 'interrupción del embarazo' y 'aborto', aunque la acción mecánica sea la misma. El aborto se define como la acción quirúrgica o procedimiento que se realiza con el fin específico de provocar la muerte del feto, mientras que la interrupción del embarazo se realizaría con el fin de poder procurar cuidar la vida de la madre (riesgo eminente), acción de la cual puede como consecuencia secundaria ocurrir que el feto fallezca. En este sentido, la universidad plantea una objeción de conciencia para realizar abortos, aunque caigan dentro del marco regulatorio de las tres causales, de forma electiva. 